\title{
Terapia Ocupacional Social: dilemas e possibilidades da atuaçáo junto a Povos e Comunidades Tradicionais ${ }^{1}$
}

\author{
Samira Lima da Costa \\ Doutora em Psicossociologia de Comunidades e Ecologia Social, \\ Universidade Federal do Rio de Janeiro - UFRJ, Professora Adjunta, Departamento de Saúde, \\ Educação e Sociedade, Universidade Federal de São Paulo - UNIFESP, Santos, SP, Brasil
}

\begin{abstract}
Resumo: O presente artigo tem como proposta discutir de que formas a garantia de direitos sociais se constitui e se sustenta (ou não) junto aos Povos e Comunidades Tradicionais, tanto nas proposições das políticas públicas quanto nas dinâmicas cotidianas de algumas dessas comunidades. Os dilemas envolvendo Povos e Comunidades Tradicionais têm suas origens em conflitos socioambientais históricos, com base na disputa e nas lutas pelo direito coletivo à terra, à tradição e ao uso dos recursos naturais, em contraponto com os avanços do capitalismo, que investem na direção do direito de uso privado da terra, dos recursos e dos saberes. A Política Nacional para o Desenvolvimento Sustentável de Povos e Comunidades Tradicionais (PNPCT), embora invista na garantia de direitos, não prevê a criação de serviços, mas a inclusão dos Povos e Comunidades Tradicionais nos serviços das demais políticas, apoiada no direito à diversidade. Assim, interessa discutir de que formas - com que facilitadores e dificultadores - pode se avançar na consolidação de tal política, e que contribuições a racionalidade da terapia ocupacional social pode oferecer a esse processo. Concluímos que é necessário ampliar o debate para que a política caminhe no sentido de garantir o acesso às demais políticas, ao mesmo tempo que assegure o direito à tradição, à terra e ao uso dos recursos naturais.
\end{abstract}

Palavras-chave: Cultura, Meio Ambiente, Política Social, Terapia Ocupacional, Terapia Ocupacional/Tendências.

\section{Social Occupational Therapy: matters and action possibilities with Traditional Peoples and Communities}

\begin{abstract}
The purpose of this article is to discuss how the guarantee of social rights is established and sustained (or not) for the Traditional Peoples and Communities, both in the propositions of social public policies as well as in the daily dynamics of some of these groups. The matters involving Traditional Peoples and Communities have their historical origins in social-environmental conflicts, based on struggles for collective rights to the land, tradition and use of natural resources, in contrast to the advances of capitalism, which invest in the direction of the right for private use of the land, resources and knowledge. The Brazilian Policy for Sustainable Development of Traditional Peoples and Communities, while investing in securing rights, does not provide for the creation of services, but for the inclusion of Traditional Peoples and Communities in the services of other policies, supported in the right to diversity. Thus, it is important to discuss how - through which facilitating and hindering mechanisms - one can advance towards the consolidation such policy, and how social occupational therapy rationality can contribute to this process. It was possible to conclude that it is necessary to expand the debate so that the policy focuses on ensuring the access to other policies, also ensuring the right to the land, tradition and use of natural resources.
\end{abstract}

Keywords: Culture, Environment, Public Policy, Occupational Therapy, Occupational Therapy/Trends.

Autor para correspondência: Samira Lima da Costa, Departamento de Saúde, Educação e Sociedade, Universidade Federal de São Paulo - UNIFESP, Campus Baixada Santista, Rua Silva Jardim, 136, Vila Mathias, CEP 11015-020, Santos, SP, e-mail: biasam@ uol.com.br 
A História pode ser encarada de dois lados e dividida em História da Natureza ou História dos Homens. Mas os dois lados náo podem ser separados do tempo; enquanto houver homens, a História da Natureza e a História dos Homens se condicionarão reciprocamente. (MARX e ENGELS, 1989, p. 23-24).

\section{Breve histórico}

A Constituição de 1988 é conhecida como constituição cidadã devido ao seu caráter essencialmente centrado na garantia de direitos universais dos brasileiros, tendo gestado o Sistema Único de Saúde, criado bases para relações federativas equilibradas, e possibilitado o processo de implantação de sistemas nacionais de educação e de assistência social, entre outras conquistas. Desde então cabe ao Estado, apoiado em suas diferentes esferas e no controle social, buscar meios de oferecer e promover acesso aos cidadãos brasileiros daquilo que, constitucionalmente, já está garantido: os direitos sociais.

Entretanto, a garantia de direitos sociais, no Brasil, passa necessariamente pelo reconhecimento da múltipla constituição do povo brasileiro, que

[...] abriga uma diversidade social e cultural que se expressa pela multiplicidade de comportamentos, institucionalidades sociais, línguas, etnias, saberes e modos de vida presentes em nosso país (SILVA, 2007, p. 7).

Já em 1988 a Constituição avançava no sentido de reconhecer os povos indígenas e quilombolas, componentes fundantes da sociedade brasileira e para os quais reserva direitos específicos. Entretanto, este é o início de uma longa jornada em busca da real caracterizaçáo da diversidade sociocultural do povo brasileiro. Assim,

[...] ao movimento do reconhecimento e implantação de direitos universais, devemos acrescentar aquele de reconhecimento das singularidades deste multiculturalismo. Em razão de processos históricos diferenciados, segmentos da sociedade brasileira desenvolveram modos de vida próprios e distintos dos demais, ocasionando ao mesmo tempo riqueza sociocultural e invisibilidade perante a sociedade e as políticas públicas de modo geral. (SILVA, 2007, p. 7).

Desta forma, entendendo a necessidade de sustentar e ampliar os avanços já garantidos na constituição, o Brasil realizou, nos últimos anos, uma série de encontros com o objetivo de discutir e socializar o debate acerca dos povos e das comunidades tradicionais nacionais. Tal processo teve como seu principal produto a Política Nacional para o Desenvolvimento Sustentável de Povos e Comunidades Tradicionais, aprovada em 2007 (BRASIL, 2007).

A Terapia Ocupacional Social, se colocando a serviço das reflexóes e práticas que se apóiam nas lutas sociais pela garantia de direitos, participa da discussão sobre os Povos e Comunidades Tradicionais - PCT, buscando construir e consolidar, em seu arcabouço profissional, a ocupação como direito social. Cabe, para tanto, pensar o que está se colocando aqui como terapia ocupacional social, bem como em que conceito de ocupação se está pautando o debate da garantia de direitos, neste recorte específico.

Neste trabalho, considera-se como Terapia Ocupacional Social aquela que toma como base a complexidade das trocas sociais e os contextos sóciohistóricos, investindo na elaboração participativa de projetos que promovam a garantia de direitos que ampliem a potência das atividades do cotidiano como formadoras e reguladoras das relaçóes entre pessoas, ambientes e contextos (COSTA, 2008).

Assim, o trabalho do terapeuta ocupacional social com povos e comunidades tradicionais parte do princípio de que a ocupaçáo, entendida como direito social, é aquela que, coletivamente, significa e produz significado social. Dessa forma, a expressão ocupação tradicional será aqui tratada em dois sentidos. Por um lado, a ocupaçáo tradicional entendida como prática significante e produtora de patrimônio (material e imaterial), caracterizada pelo trabalho como mediador entre o ser humano e a natureza. Por outro lado, a ocupação tradicional entendida como apropriação e uso coletivo do solo e dos recursos naturais, na via contrária à lógica da ocupação de territórios para uso privado, hegemônica na construção capitalista das relaçóes sociais.

\subsection{A Política Nacional para o desenvolvimento sustentável de povos e comunidades tradicionais}

Em 2006 o Governo Federal instituiu, por Decreto Presidencial, a Comissão Nacional de Desenvolvimento Sustentável dos Povos e 
Comunidades Tradicionais - CNPCT. Trata-se de um

[...] fórum de composição paritária criado pela Presidência da República visando, justamente, à elaboração e implementação de uma Política Nacional que reflita tal diversidade. (BRASIL, 2007, p. 2).

A Política Nacional para o Desenvolvimento Sustentável de Povos e Comunidades Tradicionais -PNPCT foi instituída em 2007, a partir do Decreto 6.040 do Governo Federal. Em seu texto, os principais termos estão assim descritos:

- Povos e Comunidades Tradicionais: grupos culturalmente diferenciados e que se reconhecem como tais, que possuem formas próprias de organização social, que ocupam e usam territórios e recursos naturais como condição para sua reprodução cultural, social, religiosa, ancestral e econômica, utilizando conhecimentos, inovaçóes e práticas gerados e transmitidos pela tradição;

- Territórios Tradicionais: os espaços necessários à reprodução cultural, social e econômica dos povos e comunidades tradicionais, sejam eles utilizados de forma permanente ou temporária, observado, no que diz respeito aos povos indígenas e quilombolas, o disposto na Constituição Federal;

- Desenvolvimento Sustentável: o uso equilibrado dos recursos naturais, voltado para a melhoria da qualidade de vida da presente geração, garantindo as mesmas possibilidades para as geraçôes futuras (BRASIL, 2007).

É importante ressaltar que, em princípio, a PNPCT náo prevê a criação de serviços específicos, mas a garantia de a inclusão dos Povos e Comunidades Tradicionais nos programas, serviços e equipamentos das demais políticas, apoiada em seu direito à diversidade (cultural, social, produtiva, ambiental e relacional). Visa apontar náo apenas os direitos sociais a serem garantidos, mas também os meios de garantia da diversidade. O objetivo geral da PNPCT está assim descrito:

Promover o desenvolvimento sustentável dos Povos e Comunidades Tradicionais, com ênfase no reconhecimento, fortalecimento e garantia dos seus direitos territoriais, sociais, ambientais, econômicos e culturais, com respeito e valorização à sua identidade, suas formas de organização e suas instituiçóes. (BRASIL, 2007, p. 3).
Entretanto, para se estabelecer linhas de atuação que garantam à efetivação da política, é preciso localizar e dar centralidade aos conflitos que envolvem, atualmente, os Povos e Comunidades Tradicionais, no Brasil. Assim, torna-se também relevante identificar os marcos teórico-conceituais que fundamentam esta discussão.

\subsection{Desenvolvimento e sustentabilidade}

Ao longo de todo o século XX o mundo assistiu ao aparecimento e ao crescimento das cidades. Em movimentos contemporâneos antagônicos, vimos por um lado as cidades e suas periferias se instalando ao redor do mundo e, por outro, as iniciativas de proteção ambiental investindo em ordenar e/ou desacelerar esse processo. As divergências entre aquilo que se entendia por crescimento da sociedade e o que se instituía como proteção do ambiente natural produziram e alargaram a distância entre sociedade e natureza, ao mesmo tempo que naturalizavam tal polaridade. Entretanto, a partir das últimas décadas do século $\mathrm{XX}$, a complexidade desta questão vem colocando estes dois polos na mesma mesa de negociaçóes, provocando reflexôes e açóes principalmente voltadas para a lógica da sustentabilidade, da proteçáo social e do desenvolvimento local (DIAS, 1994).

Entre os anos de 1970 e 1980, com a expansão industrial no Brasil e com as políticas de relações internacionais, a noção de desenvolvimento estava diretamente ligada à ideia de crescimento econômico (MACIEL et al., 2003). Como lembra Layrargues,

[...] o capitalismo sempre entendeu a natureza como um elemento passível de ser privatizado e transformado em mercadoria, pois o produto ambiental, enquanto 'recurso natural', pode ser apropriado individualmente. (2000, p. 102).

Esteticamente, a expressão deste desenvolvimento se configurava na "europeização" das cidades, criando um padrão homogêneo do que se chama ocidente. Esta perspectiva de desenvolvimento estava vinculada principalmente ao desenvolvimento econômico e à uniformização dos espaços públicos (COSTA, 2008).

Contudo, na medida em que se avança e se consolida a lógica do desenvolvimento pelo crescimento econômico outra questáo ambiental emerge: as interrogaçóes acerca do impacto que a devastação ambiental poderia gerar. Surgem no mundo, a partir da década de 1960, as preocupaçóes com a preservação do ambiente natural (DIAS, 1994). No Brasil, essa onda cresce com menor velocidade, 
ganhando adeptos durante o período militar (junto aos demais movimentos contraopressivos, como o feminismo e o antirracismo, surge o movimento ecológico no Brasil). Os olhos do mundo se voltam para a Amazônia, e os olhos da elite brasileira (econômica, intelectual e política) se voltam para as regiōes que, aparentemente, mantinham intocados seus ambientes naturais: áreas ribeirinhas, áreas de reserva e proteção ambiental, regióes extrativistas, entre outras.

Com isso, diante do aparecimento e da constatação de inúmeros problemas socioambientais, surgiram, a partir dos anos 1970 e 1980, várias propostas alternativas à ideia inicial de desenvolvimento centrada no crescimento econômico, entre as quais o Desenvolvimento Sustentável. Em 1987, o Relatório da Comissão Mundial sobre o Meio Ambiente, "O Nosso Futuro Comum" Brundtland, divulgou amplamente o conceito de Desenvolvimento Sustentável, apontando mudanças nos valores e nas estruturas políticas. Todavia, apresentava poucos questionamentos à dinâmica econômica, muito embora os problemas sociais e ambientais evidenciados sejam principalmente consequências da exploraçáo econômica e da produçáo de desigualdade.

Atualmente o Desenvolvimento Sustentável tornou-se palavra-chave - quando não palavra de ordem - em discursos e políticas globais e locais, ganhando o status de temática geral referente a toda noçáo de desenvolvimento que considere, de alguma forma, a questão ambiental e a questão social, ainda que de diferentes formas e com diferentes intensidades.

D’Ávila Neto (2005) questiona a forma como esse conceito foi concebido e disseminado:

$\mathrm{Na}$ ótica do desenvolvimento sustentável preconizada pelos países mais ricos, algumas das importantes reservas dos países mais pobres devem permanecer intocadas como "reservas da humanidade", o que levará, certamente, a aumentar as estatísticas de desigualdades. São os próprios organismos internacionais que constatam uma "globalização fragmentada", que se evidencia hoje, cada vez mais, tanto em regiôes menos desenvolvidas como em países mais desenvolvidos. (D’ÁVILA NETO, 1998, p. 2).

É preciso colocar em evidência esses impasses intrínsecos às políticas propostas em âmbito internacional, com foco de intervenção especificamente voltado para os países da África e da América Latina. Tais proposiçōes, entre as quais as cartas de compromisso com o Desenvolvimento
Sustentável (assinadas e reiteradas a cada nova Conferência Internacional sobre o Meio Ambiente), por um lado inserem em suas perspectivas de "proteção ambiental" a limitação da soberania desses países, e por outro não questionam a lógica da distribuição de bens que provocou a diferenciação entre países pobres e países ricos.

\section{Conflitos socioambientais}

As áreas protegidas já existiam desde o Brasil Colônia, com interesses econômicos e políticos. A lei criada por D. João VI proibia retirar árvores das florestas, pois as madeiras consideradas de qualidade pertenciam ao rei e eram mais adequadas para alimentar o arsenal de guerra - lei que originou o termo "madeira de lei" (JARDIM..., 2010; PEREIRA, 2012).

Em menor escala, mas igualmente antiga no Brasil, é a proteçấo ambiental com fins científicos. O primeiro Jardim Botânico do Brasil, no Rio de Janeiro, nasceu de um projeto de D. Joáo VI para reunir em um mesmo espaço plantas exóticas, do Brasil e de outros lugares do mundo, para serem apreciadas e estudadas por seus convidados (PEREIRA, 2012).

Foi no decorrer da década de 1980, com o processo de redemocratização nacional, que o país se inseriu como um dos protagonistas dessa discussão, no cenário mundial. Nesse período, novos movimentos de proteção ambiental se estabeleceram no Brasil, e ganham grande força a partir da Convenção das Naçôes Unidas Rio-92. Surgem projetos de toda ordem, principalmente para criar ou reestruturar Unidades de Conservação e áreas protegidas. Atualmente existem muitas modalidades de área protegida no Brasil, como: parques municipais, estaduais e federais; reservas; áreas de proteção ambiental; território indígena e quilombola; patrimônio ambiental etc.

Ocorre que, tanto a criação de novas áreas de proteçáo quanto a mudança de postura com relação às já existentes, produziram novos e grandes conflitos socioambientais. Regióes que antes pareciam pouco interessar ao centro urbano (ou ao centro do capital), que mantinham ainda conservadas muitas de suas características ambientais, passaram a ser interpretadas como possíveis lugares de preservação ambiental, o que significa ausência humana, ou presença altamente monitorada e regulada. Assim, povos que viviam da caça, da pesca e da extraçáo vegetal direta passaram por um processo de criminalização de sua tradição ocupacional, 
ou de seu trabalho tradicional. Por outro lado, as atividades hegemônicas de crescimento econômico e de produção de desigualdade passaram a passos largos dos processos de responsabilização, ainda que evidentemente ligadas aos conflitos socioambientais emergentes.

Lembrando Layrargues (2006), o movimento de culpabilização e criminalização das comunidades mais vulneráveis é uma estratégia que protege e mascara as desigualdades sociais que estão por trás de todo esse processo. Ao se identificar, de forma maciça e uniforme, que a culpa dos problemas ambientais é da Humanidade como um todo e das comunidades extrativistas, neste caso em particular, perde-se de vista as relaçốes capitalistas instaladas como questão de fundo, nos problemas ambientais.

A possibilidade de se perceber a categoria trabalho como mediadora da relaçáo do ser humano com a natureza fornece meios para que o exame das relaçóes produtivas e mercantis revele as singularidades dos atores sociais, permitindo uma distinção mais acurada do causador (e da vítima) da crise ambiental do que simplesmente 'a humanidade'. (LAYRARGUES, 2000, p. 78).

Assim, parece pouco esclarecedor tratar de tais questóes apenas do ponto de vista dos problemas ambientais, a partir de discursos fragilmente apoiados nas práticas antiecológicas de pequenos grupos de ocupação tradicionalmente extrativista.

Antes, cabe aqui buscar entender tais situaçóes como conflitos socioambientais, fomentados pelo capital através dos processos de privatização do uso de bens coletivos (como os recursos naturais), da marginalização de grupos socialmente vulneráveis e da produção de desigualdade.

A repartição dos benefícios (a geração de riqueza) e prejuízos (a geração de danos e riscos ambientais) do acesso, apropriação, uso e abuso da Natureza e recursos ambientais em geral, através do trabalho na sociedade capitalista, é sempre mediada por relaçóes produtivas e mercantis e, como tal, está sujeita à assimetria do poder nas relaçóes sociais, expondo ao risco ambiental os grupos sociais vulneráveis às condiçóes ambientais em processo de degradação (como populaçóes marginalizadas nos centros urbanos), ou dependentes de recursos naturais em processo de exaustáo (como populaçôes indígenas), agravando a já delicada situação de opressão social e exploração econômica a que tais grupos sociais são impostos pelos setores dirigentes. (LAYRARGUES, 2006, p. 81).
Em todo o Brasil essa tem sido uma questão importante. Ainda com Layrargues, sobre sociedade e meio ambiente,

[...] o que importa é que a questão ambiental nos países de Terceiro Mundo converge e se complementa com a demanda da pauta social, e isso decididamente não pode passar desapercebido". (LAYRARGUES, 2006, p. 101).

Esse autor comenta que essa é uma especificidade da América Latina, onde as questôes ambientais têm carregado um forte componente revelador das diferenças sociais.

\section{Comunidades e tradições}

Tomando como foco as comunidades tradicionais e partindo do eixo dos conflitos socioambientais, que reafirmam e evidenciam a complexidade das relaçóes entre grupos, culturas e recursos naturais, é preciso discutir o conceito de comunidade, não como delimitaçáo espacial, mas como construção coletiva de identidade.

Para Giralda Seyferth (2000), é importante discutir os usos contemporâneos desse conceito, reapropriado enquanto categoria social. $\mathrm{O}$ conceito migrou entre as várias ciências, sendo também utilizado por Organizaçôes Governamentais e Não Governamentais, tornando-se uma noção corrente no vocabulário político de distintos segmentos sociais e no do Estado, assim como do senso comum e intelectual.

Neste processo de 'migração' a noção de comunidade perde seu caráter de unidade em si, de uma forma de relaçáo social, passando a ser utilizada para designar certos fenômenos de cultura, reportável a sistemas de representação e marcadores identitários. (SEYFERTH, 2000, p. 3).

$\mathrm{O}$ argumento do desaparecimento da comunidade era central no trabalho de Ferdinand Tönnies (1957), tido como o fundador da teoria da comunidade. Ele apresentou os retratos ideais-típicos desta forma de associação social, oferecendo um estudo de contrastes entre a natureza solidarística de relaçóes sociais na comunidade e as relaçóes em grande escala e impessoais nas sociedades industrializadas.

Desta forma, Tönnies (1957) introduziu o dualismo "sociedade (Gemeinschaft)/comunidade (Gessellschaft)" no discurso científico contemporâneo. Tönnies propóe que o conceito de sociedade corresponda à vontade consciente e nascida do 
arbítrio dos respectivos membros, enquanto o de comunidade corresponderia a uma vontade essencial ou orgânica.

D`Ávila Neto, entretanto, entende que esta leitura dicotômica seja insuficiente, uma vez que tanto na "comunidade" quanto na "sociedade", há a presença dos movimentos de unificação e de fragmentaçáo, colocadas por Tönnies (1957) como polos antagônicos.

O conceito de comunidade ganha uma importante dimensão. Sua discussão não se restringe a um universo fechado, a uma unidade que engendra iguais ligados pela solidariedade. Comunidade e Sociedade deixam de ser tipologias antagônicas, do mesmo modo que relaçóes macro e microssociais. (D’ÁVILA NETO, 2002, p. 1).

É preciso explicitar essa ampliação dos conceitos de Comunidade e de Sociedade, proposta por D'Ávila Neto (2002) para tratar dos PCT, pois, por se tratarem de Comunidades Tradicionais, o risco de entendê-las como coesas e homogêneas a priori empobrece a compreensão mais ampla e problematizadora que aqui se apresenta.

A partir da compreensão de que uma Comunidade Tradicional compartilha determinado território, necessário "à sua reprodução cultural, social e econômica" e que tal território, bem como seus recursos naturais, se apresentam como condição para a utilização de "conhecimentos, inovações e práticas gerados e transmitidos pela tradição" (BRASIL, 2007), cabe aqui apresentar as perspectivas do território compartilhado e da produçáo de tradições. O território compartilhado pode ser compreendido como o espaço físico e afetivo no qual ocorrem as relaçóes sociais cotidianas do sujeito, marcadas pela convivência presencial. Tais territórios compartilhados participam da construção das memórias deste coletivo, elemento fundamental da produção de suas tradiçōes (COSTA, 2008).

A esse respeito, Halbwachs (2006) explica como o espaço de convivência e as imagens espaciais desempenham um importante papel na memória coletiva:

O lugar ocupado por um grupo não é como um quadro-negro no qual se escreve e depois se apaga números e figuras. Como a imagem do quadro-negro poderia recordar o que nele traçamos, se o quadro-negro é indiferente aos números e se podemos reproduzir num mesmo quadro as figuras que bem entendermos? Não. Mas o local recebeu a marca do grupo, e vice-versa. Todas as açóes do grupo podem ser traduzidas em termos espaciais, o lugar por ele ocupado é apenas a reunião de todos os termos. Cada aspecto, cada detalhe desse lugar tem um sentido que só é inteligível para os membros do grupo, porque todas as partes do espaço que ele ocupou correspondem a outros tantos aspectos diferentes da estrutura e da vida de sua sociedade, pelo menos o que nela havia de mais estável. (HALBWACHS, 2006, p. 161).

Lynch (1982) enumera alguns fatores que influenciam a imagem das cidades e das comunidades: o significado social de uma área, sua função, sua história e o seu nome. Assim, para este autor, os limites geográficos podem funcionar como "referências secundárias", tendo as relaçóes pessoais e grupais como demarcadores de territórios e papéis (LYNCH, 1982, p. 37). Portanto, o território compartilhado constitui feixes de relaçóes, ora mais ora menos solidários ou conflituosos entre si.

As Comunidades Tradicionais se definem

[...] pelo uso sustentável da terra, pelo destino da sua produção e o seu vínculo territorial, incluindo sua situação fundiária, pela importância que os ciclos naturais têm nas suas práticas produtivas, pelo uso que fazem dos recursos renováveis e as práticas de uso comunitário dos mesmos, pelo seu conhecimento profundo do ecossistema no qual vivem e pelo uso de tecnologias de baixo impacto ambiental, por sua organizaçáo social, na qual a família extensa representa papel importante, também por suas expressões culturais e as inter-relaçôes com outros grupos da região. (SILVA, 2007, p. 8, grifo nosso).

Pode-se compreender, desta forma, que o uso continuado e sustentável dos recursos naturais e o compartilhamento histórico dos territórios geográfico e relacional - se constituem como campo para produção (ou invenção comunitária) da tradição.

A tradição se pauta na relação entre determinadas práticas coletivas e sua continuidade no tempo, ou seja, na constituição de certa antiguidade e permanência de determinadas práticas coletivas, produzidas e produtoras de identidade comunitária. Porém, a antiguidade das práticas tradicionais é demarcada a partir da necessidade de se constituir a tradição como valor e a prática como referência. A própria "antiguidade" seria, assim, uma invenção que ganha vida a partir da necessidade de afirmar identidades coletivas, desenhando fronteiras entre a comunidade e o de fora, entre a tradição e o que não é tradicional. A este respeito, Bauman (2003) afirma que: 
Só depois que os marcos de fronteira estão cravados e as armas estão apontadas contra os intrusos é que os mitos sobre a antiguidade das fronteiras são inventados e as recentes origens culturais e políticas da identidade são cuidadosamente encobertas por "narrativas de gênese”. (BAUMAN, 2003, p. 21).

Assim, entende-se aqui que tais fronteiras não são traçadas para defender a singularidade das identidades já existentes, mas, ao contrário, as identidades "comunitárias" são consequências do processo de estabelecimento de fronteiras.

\subsection{Diversidade, tradição e desigualdade}

A partir das características que dão aos Povos e Comunidades Tradicionais um tom particular e ao mesmo tempo representativo dos diversos PCT nacionais, parece se tornar relevante a discussão sobre como vem sendo tratada a questáo da diversidade e da desigualdade.

Já em meados do século XX a invenção da igualdade como categoria de qualidade de relaçóes entre povos e comunidades foi substituída pela noção de equidade (D’ÁVILA NETO, 1998). Isso ocorreu devido ao fracasso da tentativa de se alcançar, na prática, as expectativas iniciais das Organizaçóes Mundiais para os países do Sul, que envolviam uma proposta de igualdade. Diante da constataçáo de que essa expectativa era inalcançável, a Comissão Econômica para a América Latina e Caribe (CEPAL) propôs uma mudança nos objetivos, como informa D’Ávila Neto:

A CEPAL, diante do fracasso das políticas para uma melhor distribuição de renda adotadas na América Latina, propõe a "transformação produtiva com equidade", onde se pretende substituir Igualdade por Equidade, cujo conceito pretende ser Igualdade com Diversidade. Nos pressupostos da proposta está a questáo de um desenvolvimento que nasce com caracterizações regionais, de dentro para fora, fundado no "progresso técnico", e cuja principal forma de obter é pela educação. (D’ÁVILA NETO, 1998, p. 2).

A proposta de Igualdade com Diversidade dá origem às discussóes sobre o multiculturalismo. A respeito deste novo conceito, Bauman (2003) comenta que se trata de uma proposiçấo na qual se transfere às minorias culturais a responsabilidade de conquistar seu próprio espaço na cultura global, se afirmando enquanto cultura local. Este autor aponta a seguinte concepção para multiculturalismo:

A resposta mais comum dada em nossos dias pelas classes ilustradas e formadoras de opinião para a incerteza do mundo sobre os tipos de valores que merecem ser apreciados e cultivados, e sobre as direçôes que devem ser seguidas com férrea determinação. [...] Numa palavra, a invocação do "multiculturalismo", enquanto parte das classes ilustradas, essa encarnação contemporânea dos intelectuais modernos, quer dizer: Perdão, mas não podemos resgatá-lo da confusão em que você se meteu. Sim, há confusão sobre valores, sobre o sentido de "ser humano", sobre as maneiras certas da vida em comum; mas depende de você encontrar seu próprio caminho e arcar com as consequências caso náo goste dos resultados. (BAUMAN, 2003, p. 112).

Desta forma, a sociedade contemporânea teria criado o conceito de multiculturalismo como solução para a difícil tarefa de garantir a igualdade com direito à diversidade sem, no entanto, comprometer as classes que o autor chama de "ilustradas" e seu poder hegemônico.

Gonçalves e Silva (1998, p. 14) afirmam que

[...] o multiculturalismo enquanto movimento de ideias resulta de um tipo de consciência coletiva, para a qual as orientaçóes do agir humano se oporiam a toda forma de 'centrismos' culturais, ou seja, de etnocentrismos.

Porém, estes mesmos autores, admitem que as posiçôes com relação ao multiculturalismo estão divididas. Para alguns, o multiculturalismo é considerado uma proposta ingênua e leviana, considerando que parte de uma falsa consciência acerca dos reais problemas culturais (GONÇALVES; SILVA, 1998).

Entende-se que, embora o multiculturalismo possa realmente servir de ponto de partida para o fortalecimento de alguns movimentos de descentralização cultural, pode sim acabar por constituir uma forma ingênua de considerar as diferenças, uma vez que se deixa de questionar os problemas em torno do conceito.

Há um estado de manutenção da miséria e da desigualdade que em alguns momentos esconde-se atrás do título de multiculturalismo, incentivando este processo que não é, como faz parecer, de garantia de direito à diferença, mas sim de exclusão. Bauman (2003) discute que, 
O que a visão "culturalista" do mundo não menciona é que a desigualdade é sua própria causa mais poderosa, e que apresentar as divisóes que ela gera como um aspecto inalienável da liberdade de escolha, e não como um dos maiores obstáculos a essa liberdade de escolha, é um dos principais fatores de sua perpetuação. (BAUMAN, 2003, p. 99).

A desigualdade corre o risco de passar a ser mantida sob a justificativa de ser uma cultura regional que deve ser preservada, como se a miséria e a falta de oportunidades pudessem ser consideradas "patrimônio cultural".

Com o advento da era industrial, o papel de assimilação da pobreza passou a ser exercido pelas práticas higienistas e de "surveillance" dos estados-naçôes, que estão na origem das políticas atuais do bem estar social (welfare state). Mas essas políticas não respondem mais às necessidades que agora passaram a ser globais: o número de despossuídos aumenta cada vez mais, sem nenhuma "justificativa" que possa assimilá-los, como outrora, e o que é pior, num mundo onde seria considerado um totalitarismo inaceitável pregar a "não igualdade”. (D’ÁVILA NETO, 1998, p. 2).

Eis uma armadilha do conceito de multiculturalismo: se por um lado as culturas minoritárias podem lançar mão dele para se afirmarem e se manterem como categoria social com uma cultura própria, fazendo uso da perspectiva da diversidade com equidade; por outro lado esta noção pode também ser utilizada para a manutenção de condiçóes precárias de vida, compreendidas (não necessariamente pela população em questão) como "características locais".

Ao se defender o diverso não se pode cair num pluralismo indiferenciado, em que as vivências pessoais e as lutas sociais se deem numa história diluída e desconexa, na qual a negação, a confrontação de teorias e argumentos e a superação transformadora tornam-se impossíveis de se realizarem. Isso seria recair num relativismo absoluto e no atomismo de iniciativas que passam a ser vistas como válidas em si mesmas, posturas que em nada favorecem a consolidação da educaçáo como atividade cidadã. (LOUREIRO, 2004, p. 22).

A noção de multiculturalismo, ainda que se apresente como forma de defender os direitos de grupos discriminados, muitas vezes acaba por determinar uma prática que naturaliza a própria desigualdade, confundindo tradição com estagnação.
É preciso lembrar que as tradiçóes de um povo mudam, e não é o movimento de evitar a mudança que garante a manutenção da tradição, mas sim o direito à tradição e à sua inevitável mudança. Não se trata, portanto, de defender o direito às tradiçôes imutáveis.

A este movimento de manutenção das características regionais a todo custo Dembicz chamou de Revolución Regional,

[...] nombre com que designa aquí a la tendencia y moda omnipresente de 'regionalizar' y aplicar el 'paradigma regional' a todo, independentemente de las necessidades objetivas". (DEMBICZ, 2000, p. 19).

Para Magnani (1998), a preocupação dos estudiosos que se ocupam de práticas tradicionais, os chamados "folcloristas", tem sido "descobrir" e "preservar" práticas culturais antigas. Para este pesquisador, nos estudos dos folcloristas toda e qualquer mudança nas práticas tradicionais é vista como deturpação da forma e pureza original.

Apresentam-se como defensores de uma cultura popular, mas paradoxalmente são os que mais passam atestados de óbito a essa mesma cultura, por recusarem-se a assimilar suas transformaçóes". (MAGNANI, 1998, p. 26).

Mais relevante do que constatar as supostas perdas de autenticidade, porém, seria analisar os costumes e valores na forma como se apresentam na atualidade, pois a cultura é mais um processo do que uma condição estática no tempo e no espaço. As transformaçóes sociais são inerentes ao desenvolvimento que, como já vimos, acontece a todo o momento.

A este respeito, Benjamin (1999) nos convida a desviar nosso olhar daquilo que é invariável para aquilo que muda, constatando que, ainda assim, continua a tradição. Caso contrário, há o surgimento de uma nova concepção de multiculturalismo, na qual a cultura tradicional é, para a mídia, um “adereço exótico" (BENJAMIN, 1999). É o que parece ocorrer, em alguns aspectos, com relação aos PCT no Brasil.

As tradiçóes dos povos em questáo parecem, aos poucos, se transformarem em patrimônio cultural, e os saberes tradicionais vão sistematicamente sendo "resgatados" e valorizados também como patrimônios da humanidade o que, contraditoriamente, pode alienar a tradição, que passa a ser vista como um produto. 
4 PCT no Brasil: dilemas, contradições e produção de estratégias de enfrentamento

Atualmente, no Brasil, ainda são poucos os povos de ocupação tradicional que já têm reconhecido seu direito de extração de recursos naturais. Alguns pela caracterização como povo indígena ou quilombola; outros pela criação de reservas extrativistas, como em muitas comunidades caiçaras; outros ainda pela aliança com os órgãos de defesa ambiental (principalmente o IBAMA), no sentido de garantir a coleta sazonal, respeitando o ciclo de reproduçáo do objeto da extraçáo, como os catadores de caranguejo e os seringueiros. Tais situaçóes, longe de garantirem o direito à ocupação tradicional, trazem novos dilemas, entre as quais podemos destacar algumas:

\subsection{Comunidades que vivem dentro ou no entorno de Unidades de Conservação}

No entorno e no interior de Unidades de Conservação, as tensóes se colocam como se o conflito estivesse colocado, de forma geral e indiferenciado, na relação sociedade-natureza, no qual alguns se posicionam em prol do desenvolvimento e das garantias sociais e outros se manifestam, do lado oposto, em defesa da preservaçáo ambiental. A este respeito, é importante recolocar a questão, sem deixar de fora os lugares políticos dos quais se está falando. A quem interessa o recurso natural? A serviço de quem (e de quê) se defende, por um lado, a proibição da caça e do desmatamento para grupos extrativistas locais e, ao mesmo tempo, se permite a privatizaçáo da exploração de bens coletivos, como a água e o solo?

\subsection{Comunidades que vivem em territórios próprios, reconhecidas como "aldeias", ou povos aldeiados}

Muitos povos e comunidades tradicionais encontram-se, atualmente, em processo de luta pelo seu reconhecimento, enquanto outros, ainda que já oficialmente reconhecidos, enfrentam cotidianamente guerrilhas fundiárias. Alguns grupos quilombolas e indígenas conseguiram seu reconhecimento e garantia de terras, e se encontram em situação de pobreza e de miséria, o que se materializa pela crescente favelizaçấo das aldeias. A falta de trabalho, a dificuldade de manutenção e valorização da tradição e, ao mesmo tempo, inviabilidade ou precariedade de inserção no mercado de trabalho urbano, vem progressivamente criando situações de fuga, abandono, dependência química e até suicídio (GUMS, 2005). As estratégias de sobrevivência colocadas pela sociedade contemporânea (ocidental capitalista) estão relacionadas à propriedade e ao acúmulo de bens. Entretanto, embora sejam "donos" das terras, estas, muitas vezes, não estão disponíveis para comercialização, produzindo outros impasses. Além disso, alguns desses povos, como identificado por Macedo (2010) em Ubatuba, se fixam ao solo a partir do termo de cessáo de uma área (como a instalação de uma reserva indígena, por exemplo), mas sua prática tradicional de ocupação estava, anteriormente, assentada na prática da itinerância e sazonalidade.

\subsection{Comunidades de ocupação tradicional em periferia urbana}

Muitas comunidades tradicionais localizam-se em regióes periféricas a centros urbanos, como os pescadores artesanais (COSTA, 2008) ou produtores artesanais de panelas de barro (ALVARENGA, 2002), por exemplo. O crescimento das cidades, o desenvolvimento econômico e a permanente exploração dos recursos naturais pelos grandes empreendimentos provocam a diminuiçáo da oferta da matéria-prima. A falta do recurso primário para a sustentação da ocupação tradicional tensiona tais populaçôes em direção a outros meios de geração de renda e sustento, assumindo lugares marginais no mercado de trabalho urbano, uma vez que suas qualificaçóes tradicionais perdem valor. Por outro lado, as características do trabalho urbano demandam qualificaçóes que não possuem, forçando sua inserção na rede produtiva de forma bastante precária. Além dos efeitos imediatos, esse processo também abala profundamente um dos pilares da construção permanente da tradição: a valoração do saber tradicional pelas novas geraçóes, o que, por sua vez, desencadeia um processo contínuo e crescente de descontinuidade intergeracional.

Estas situaçôes colocam questôes para a sociedade em geral, mas principalmente para os profissionais que irão atuar em uma perspectiva de ampliação de direitos junto a essas pessoas, dentre eles o terapeuta ocupacional. Neste sentido, é preciso recolocar as perguntas, redefinindo o que é central para a reflexão dos direitos dos Povos e Comunidades Tradicionais. É preciso entender, primeiramente, o direito à ocupação, em seus dois sentidos: a 
ocupação tradicional, enquanto práxis construída coletivamente; e a ocupação do solo, enquanto apropriação de um território. Então, com base nas discussóes já postas, cabe questionar, nas atuais políticas públicas:

- Sobre a questão social e a questão ambiental: de que sustentabilidade falamos?

- Sobre o acesso aos equipamentos: de que trabalho territorial falamos?

- Sobre a tradição e o desenvolvimento: de que ocupação falamos?

- Sobre a família: de que coletivos de convivência falamos?

Assim, torna-se necessário o conhecimento dos

[...] interesses políticos e econômicos dos diferentes sujeitos sociais e das instituiçôes, dos modos de acesso e usufruto dos recursos naturais, dos regimes de propriedade dos recursos, das opçôes tecnológicas existentes, dos impasses para a negociação, do conflito que impede o diálogo. (LAYRARGUES, 2000, p. 95).

\section{Discussão}

Pautados em políticas públicas sociais que narram um Brasil diverso, mas normatizam um Brasil uniforme, as distribuiçôes de serviços e equipamentos não sustentam as diretrizes de serem, por um lado, referências por território identitário e, por outro, aglutinadores de vários territórios em nome de um quantitativo mínimo de famílias assistidas. O que fazer com lugares distantes? Com números pequenos de famílias? Com culturas que não se organizam em famílias?

É preciso refletir sobre a possibilidade de flexibilizar a lógica da distribuição territorial dos equipamentos por número de famílias, pensando em populaçôes com características singulares, como muitos dos Povos e Comunidades Tradicionais.

A PNPCT, recentemente aprovada, nos coloca de volta essa questáo: nessa política, o que está posto é que as demais políticas se organizarão para garantir a inclusão dessas populaçôes em sua cobertura, considerando características locais, respeitando a cultura e garantindo, entre outros, o direito de mudar, rever suas tradiçōes. Quais serão, então, as novas estratégias? Como serão repensados os serviços e equipamentos, não mais tomando o número de famílias por equipe ou a fixação de equipamentos em território como determinantes dos processos de implantação da política, mas as características locais: comunidades ribeirinhas, indígenas, quilombolas, caiçaras, rurais, povos ciganos, povos que não falam português?

Essas questóes apontam para a necessidade de se construírem estratégias que, ao mesmo tempo, protejam socialmente e potencializem politicamente os grupos que se identificam com tais questôes e demandam tais investimentos. É certo que, no interior das políticas de assistência social, saúde e educação, têm se aprofundado as reflexôes, os discursos e as normativas referentes à flexibilidade e às adequaçốes necessárias aos seus respectivos equipamentos, serviços, programas e equipes com relação às diferentes culturas encontradas em toda a extensão do País. Cabe, entretanto, colocar em foco os dilemas que o cotidiano dos Povos e Comunidades Tradicionais (também não homogêneos entre eles) enfrenta na relação entre cultura local, crescimento econômico e políticas públicas.

O terapeuta ocupacional, em diferentes contextos (MACEDO, 2010; COSTA, 2008; COSTA; FAGUNDES, 2010; REDE MOCAMBOS, 2008; PONTES, 2011; COSTA; ALVARENGA; ALVARENGA, 2007; FUNDAÇĀO..., 2004), tem sido um importante colaborador na discussão e na articulaçáo de propostas que, produzidas no interior das próprias comunidades referidas, se constituem em estratégias de potencialização da ocupação (nos dois sentidos já apresentados) como direito social. Assim, têm sido utilizados recursos como a produção individual e coletiva da memória ocupacional local; a invenção de dispositivos que contribuam para o fortalecimento de saberes e fazeres tradicionais; a potencialização de laços, redes e movimentos que se ocupam da criação e manutençâo de produtos culturais; a articulação comunitária; o investimento em atividades voltadas para a valorização do cotidiano, povoado por práticas e conhecimentos tradicionais; a produção coletiva de projetos para o desenvolvimento local sustentável; a identificação/ produção/sustentação/qualifica-ação de fluxo entre serviços que respeitem e se constituam a partir das características culturais locais; o mapeamento e acompanhamento da infância, da adolescência e dos processos de envelhecimento, considerando as rupturas intergeracionais; a garantia de direitos, inclusive de extração e de desenvolvimento; a organizaçáo coletiva do trabalho: cooperativas, associações e reservas extrativistas.

Há que se ampliar o debate para planejar equipamentos adequados às diferentes realidades, como serviços itinerantes, referências territoriais mesmo que não alcancem o número mínimo de famílias, e outros parâmetros estabelecidos. Além 
disso, é preciso criatividade e flexibilidade para propor programas que se apoiem em culturas locais, como bolsa-aldeia, em culturas nas quais a família não é nuclear; condicionalidades que prevejam ocupaçôes tradicionais, em culturas nas quais a prática coletiva seja mais central do que a inserção no mercado de trabalho; diferenciar o trabalho infantil da prática tradicional e transferência intergeracional de saberes ocupacionais, entre outros.

\section{Referências}

ALVARENGA, L. Do sururu à panela de barro: a realidade de heranças milenares. 2002. 173 f. Dissertação (Mestrado em Ciência Ambiental)-Universidade Federal Fluminense, Niterói, 2002.

BAUMAN, Z. Comunidade: a busca por segurança no mundo atual. Rio de Janeiro: Jorge Zahar Editora, 2003.

BENJAMIN, R. Culturas regionais: permanências e mudanças em tempo de globalização. In: BOLAÑO, C. R. S. (Org.). Globalização e regionalização das comunicaçōes. São Paulo: EDUC; Universidade Federal de Sergipe, 1999. p. 129-136.

BRASIL. Presidência da República. Decreto no 6.040, de 7 de fevereiro de 2007. Institui a Política Nacional para o Desenvolvimento Sustentável de Povos e Comunidades Tradicionais. Diário Oficial da República Federativa do Brasil, Poder Executivo, Brasília, DF, 8 fev. 2007. Seção 1.

COSTA, S. L. Os sentidos da comunidade: construçóes intergeracionais de memória coletiva na Ilha das Caieiras, em Vitória/ES. 2008. 337 f. Tese (Doutorado em Psicossocilogia de Comunidades e Ecologia Social)Universidade Federal do Rio de Janeiro, Instituto de Psicologia, Rio de Janeiro, 2008.

COSTA, S. L.; ALVARENGA, L.; ALVARENGA, A. M. Estudo de/com comunidades tradicionais: cultura, imagem e história oral. Revista Documenta Virtual, n. 17, p. 1-6, 2007. Disponível em: <http://www.psicologia. ufrj.br/pos_eicos/pos_eicos/arqanexos/documenta/ documenta17indice.htm>. Acesso em: 09 fev. 2012.

COSTA, S. L.; FAGUNDES, A. C. Terapia Ocupacional e Comunidades Tradicionais. In: JORNADA DE TERAPIA OCUPACIONAL DA BAIXADA SANTISITA; 1.; SIMPÓSIO DE TERAPIA OCUPACIONAL SOCIAL DA BAIXADA SANTISTA, 1., 2010, Santos. Anais... Santos: UNIFESP, 2010.

D'ÁVILA NETO, M. I. A porta, a ponte e a rede. Revista Documenta, n. 8, p. 04-18, 2002.

D’ÁVILA NETO, M. I. Os "novos" pobres e o contrato social: receitas de desenvolvimento, igualdade e solidariedade ou da solidariedade, seus mitos, laços e utopias. Arquivos Brasileiros de Psicologia, v. 50, n. 4, p. 7-13.1998.

DEMBICZ, A. El espacio entre lo local y lo global. In: LEMOS, M. T. T. B.; MORAES, N. A. (Orgs.). Memória e identidade. Rio de Janeiro: 7Letras, 2000. p. 9-14.
DIAS, G. F. Educação ambiental: princípios e práticas. São Paulo: Gaia, 1994.

FUNDAÇÃO NACIONAL DE SAÚDE - FUNASA. Notícias Funasa - Informativo eletrônico, ano 1, n. 4, p. 1-4, 2004. Disponível em: <http://www.funasa.gov. br/Web\%20Funasa/pub/boletins/pdf/inf4_funasa.pdf>. GONÇALVES, L. A. O.; SILVA, P. B. G. O jogo das diferenças: o multiculturalismo e seus contextos. Belo Horizonte: Autêntica, 1998.

GUMS, C. Suicidio na cultura Pomerana: um olhar de dentro. 2005. 76 f. Monografia (Especialiazação em Saúde Mental e Atenção Psicossocial)- Faculdade de Ciências da Saúde, Vitória, 2005.

HALBWACHS, M. A memória coletiva. São Paulo: Centauro, 2006.

JARDIM BOTÂNICO DO RIO DE JANEIRO - JBRJ. Disponível em: <www.jbrj.gov.br>. Acesso em: 12 ago. 2010.

LAYRARGUES, P. P. Educação para a gestão ambiental: a cidadania no enfrentamento político dos conflitos socioambientais. In: LOUREIRO, C. F. B.; LAYRARGUES, P. P.; CASTRO, R. S. (Orgs.). Sociedade e Meio Ambiente: a educação ambiental em debate. São Paulo: Cortez, 2000. p. 87-156.

LAYRARGUES, P. P. Muito além da natureza: educação ambiental e reprodução social. In: LOUREIRO, C. F. B.; LAYRARGUES, P. P.; CASTRO, R. S. (Orgs.). Pensamento complexo, dialética e educação ambiental. São Paulo: Cortez, 2006. p. 72-103.

LOUREIRO, C. F. B. Trajetórias e fundamentos da educação ambiental. São Paulo: Cortez, 2004.

LYNCH, K. A imagem da cidade. Lisboa: Ediçôes 70, 1982.

MACEDO, M. D. C. Jovens entre culturas: itinerários e perspectivas de jovens Guarani entre a aldeia Boa Vista e a cidade de Ubatuba. 2010. 328 f. Dissertaçáo (Mestrado em Ciências)-Faculdade de Medicina, Universidade de São Paulo, São Paulo, 2010.

MACIEL, T. M. F. B.; MOREIRA, G. M. P.; BRASIL, A.B.V. L. Desenvolvimento e des-envolvimento: o desejado e o desejável. In: D’ÁVILA, M. I.; PEDRO, R. (Orgs). Tecendo o desenvolvimento: saberes, gênero, ecologia social. Rio de Janeiro: Mauad-Bapera Editora, 2003. p. 157-166.

MAGNANI, J. G. C. Festa no pedaço: cultura popular e lazer na cidade. São Paulo: HUCITEC, UNESP, 1998. MARX, K., ENGELS, F. A ideologia Alemã. 7. ed. São Paulo: Hucitec, 1989.

PEREIRA, T. O que narram os jovens ex-integrantes do programa de responsablidade social do Jardim Botânico do Rio de Janeiro sobre a relação desta instituição com grupo ao qual pertencem, a comunidade do Horto. 2012. $104 \mathrm{f}$. Dissertação (Mestrado em Psicossocilogia de Comunidades e Ecologia Social)-Universidade Federal do Rio de Janeiro, Instituto de Psicologia, Rio de Janeiro, 2012.

PONTES, M. A. Entre os saberes técnicos e os saberes populares em saúde, na comunidade Manauara. 2011. 15 f. 
Projeto (Mestrado em Educação em Saúde)-Instituto IDEA, Rio de Janeiro, 2011. Mimeo.

REDE MOCAMBOS. Casa de Cultura Tainã e Centro de Convivência e Cooperativa Toninha. Projeto enviado para o Edital Cultura e Saúde pela Casa de Cultura Tainã e Centro de Convivência e Cooperativa Toninha - nov/2008. Campinas: REDE MOCAMBOS, 2008. Disponível em: <http://www.mocambos.org/projetos/cultura-e-saudetaina-cecco-toninha>. Acesso em: 10 nov. 2011.
SEYFERTH, G. Usos e abusos da comunidade. In: SIMPÓSIO DA REUNIÃO BRASILEIRA DE ANTROPOLOGIA, 22., 2000, Brasília. Anais... Brasília: ABA, 2000.

SILVA, M. O. Saindo da invisibilidade - a política nacional de povos e comunidades tradicionais. Inclusão Social, v. 2, n. 2, p. 7-9, 2007.

TÖNNIES, F. Community and Society: Gemeinschaft und Gesellschaft. Michigan: The Michigan State University Press, 1957.

\section{Notas}

${ }^{1}$ Parte da discussão deste trabalho foi apresentada no II Simpósio Internacional de Terapia Ocupacional Social, realizado no dia 12 de outubro de 2011, compondo a programação do XII Congresso Brasileiro de Terapia Ocupacional e IX Congresso Latino-americano de Terapia Ocupacional. 